Neuroepidemiology 2008;30:70

DOI: $10.1159 / 000115752$

\section{Fish Consumption in Relation to Stroke Risk}

\author{
$\mathrm{Ka} \mathrm{He}^{\mathrm{a}}$, Zhongqing Guo $\mathrm{o}^{\mathrm{a}} \mathrm{b}$ \\ ${ }^{a}$ Departments of Nutrition and Epidemiology, University \\ of North Carolina at Chapel Hill, Chapel Hill, N.C., USA; \\ ${ }^{b}$ Department of Preventive Medicine, Ningxia Medical College, \\ Yinchuan, PR China
}

In the Twin Veterans Study, Bravata et al. [1] reported that fish or seafood consumption was not associated with risk of stroke. In addition to the limitations the authors discussed, we think that their null findings could be at least partially explained by the composite endpoints and misclassification of the exposure.

Similar to some other previous studies, Bravata et al. [1] did not separate hemorrhagic stroke from ischemic stroke. Instead, all types of strokes plus transient ischemic attack were pooled together. Experimental and epidemiological studies suggest that long-chain omega-3 polyunsaturated fatty acids in fish or seafood may have different effects on ischemic stroke and hemorrhagic stroke [2-4]. If we combined these two types of stroke in the analysis, the results would be different according to the ratio of ischemic stroke and hemorrhagic stroke in the outcome. In other words, any potential association between fish or seafood consumption and ischemic stroke could be attenuated by including hemorrhagic stroke in the analysis.

Also, Bravata et al. [1] categorized fish or seafood consumption into 'frequently', 'occasionally' and 'infrequently' based on the information obtained in two questionnaires 13 years apart. Particularly, they used a relatively high cut-off amount - once per week - to define fish or seafood consumption groups. It might lead to misclassification of the exposure and dilute any possible association between fish and stroke. In addition, the authors compared participants who consumed fish or seafood at least once per week with those who ate fish or seafood less than once per week in the main analyses. Studies suggest that there may be nonlinear or threshold relations between fish consumption and coronary heart disease and stroke; consumption of small amounts of fish may have a beneficial effect on stroke risk, particularly ischemic stroke $[5,6]$. A possible inverse threshold association could be attenuated or eliminated if the exposure level in the reference or the control group is too high. It would better approach the unbiased associations if we could use refined categories of fish or seafood consumption and the cumulative exposure model [7] with repeated measurements in the analysis.

\section{References}

1 Bravata DM, Wells CK, Brass LM, Morgan T, Lichtman JH, Concato J: Dietary fish or seafood consumption is not related to cerebrovascular disease risk in twin veterans. Neuroepidemiology 2007;28:186-190.

2 Dyerberg J, Bang HO, Stoffersen E, Moncada S, Vane JR: Eicosapentaenoic acid and prevention of thrombosis and atherosclerosis? Lancet 1978;2:117-119.

3 Hirai A, Hamazaki T, Terano T, Nishikawa T, Tamura Y, Kamugai A, Jajiki J: Eicosapentaenoic acid and platelet function in Japanese. Lancet 1980;2:1132-1133.

4 He K, Song Y, Daviglus ML, Liu K, Van Horn L, Dyer AR, Goldbourt U, Greenland P: Fish consumption and incidence of stroke: a metaanalysis of cohort studies. Stroke 2004;35:1538-1542.

5 He K, Rimm EB, Merchant A, Rosner BA, Stampfer MJ, Willett WC, Ascherio A: Fish consumption and risk of stroke in men. JAMA 2002; 288:3130-3136.

6 Mozaffarian D, Rimm EB: Fish intake, contaminants, and human health: evaluating the risks and the benefits. JAMA 2006;296:18851899.

7 Hu FB, Stampfer MJ, Rimm E, Ascherio A, Rosner BA, Spiegelman D, Willett WC: Dietary fat and coronary heart disease: a comparison of approaches for adjusting for total energy intake and modeling repeated dietary measurements. Am J Epidemiol 1999;149:531-540.

$\mathrm{Ka} \mathrm{He}, \mathrm{MD}, \mathrm{ScD}$

Departments of Nutrition and Epidemiology

University of North Carolina at Chapel Hill

2202 McGavran-Greenberg Hall, Campus Box 7461

Chapel Hill, NC 27559 (USA)

Tel. +1 919843 2476, Fax +1 919966 7216, E-Mail kahe@unc.edu

\section{KARGER \\ Fax +41613061234 \\ E-Mail karger@karger.ch}

www.karger.com (c) 2008 S. Karger AG, Basel

0251-5350/08/0301-0070\$24.50/0

Accessible online at:

www.karger.com/ned 